\title{
Lignin from an integrated process consisting of liquid hot water and ethanol organosolv: Physicochemical and antioxidant properties
}

\author{
Michele Michelin a,*, Simon Liebentritt ${ }^{\mathrm{a}, \mathrm{b}}$, António A. Vicente ${ }^{\mathrm{a}}$, José António Teixeira a \\ a Centre of Biological Engineering, University of Minho, Campus Gualtar, 4710-057 Braga, Portugal \\ ${ }^{\mathrm{b}}$ Faculty of Technical Chemistry, TU Wien, Vienna, Austria
}

\section{A R T I C L E I N F O}

\section{Article history:}

Received 13 June 2018

Received in revised form 13 July 2018

Accepted 9 August 2018

Available online 10 August 2018

\section{Keywords:}

Lignin

Corncob

Integrated process

Autohydrolysis

Organosolv

Antioxidant

\begin{abstract}
A B S T R A C T
Corncob was successively pretreated by liquid hot water (LHW) and ethanol organosolv (EO) in an integrated process. LHW was performed at $200{ }^{\circ} \mathrm{C}$ for $30 \mathrm{~min}$, and EO was performed using uncatalyzed ethanol-water solutions, according to a design of experiments. The effects of the most influential operational variables (ethanol concentration, temperature and time) on yield and chemical composition of the fractions were assessed. Results showed the factor with the greatest effect was ethanol concentration $(p<0.05)$, leading to a high-purity lignin (86.7\%-93.1\%) with a total phenolic content of around $25 \mathrm{mg} \mathrm{GAE} / \mathrm{g}$. Moreover, the solids recovered from the high ethanol concentration conditions presented the lowest lignin contents (15.4\%-17.2\%) with good preservation of cellulose $(82.5 \%-88.6 \%$ of glucans). The lignin antioxidant capacity showed that all lignin samples presented radical scavenging activity $\left(\mathrm{IC}_{50}\right.$ of $0.17 \mathrm{mg} / \mathrm{mL}$ and $0.016 \mathrm{mg} / \mathrm{mL}$ on DPPH (2,2 diphenyl 1 picrylhydrazyl) and ABTS (2,2' azino bis( 3 ethylbenzothiazoline 6 sulphonic acid) assays, respectively) with values close to the commercial antioxidant BHT. Moreover, the chemical (FTIR) and thermal (DSC and TGA) characterization showed lignins with similar properties that were compared with lignin from direct ethanol organosolv process. Results showed that the integrated process of LHW-EO was the most effective way to obtain lignin with high purity and antioxidant capacity.
\end{abstract}

(C) 2018 Elsevier B.V. All rights reserved.

\section{Introduction}

Lignin, accounting for $20-30 \%$ in lignocellulosic materials (LCMs), is the second most abundant naturally synthesized polymer in the world. It is an amorphous and highly branched polyphenolic (aromatic) macromolecule, known to bind to cellulose and hemicelluloses [1].

During the last decades, the growing interest for green and biobased materials from LCMs has promoted an increased use of lignin in various applications, e.g. as antioxidants [2]. Since 2011, the field of antioxidants was distributed in: rubbers (and latex) - 53\%; plastics - $36 \%$; food and nutrition $-8 \%$, and oil fuels $-3 \%$ [3]. In the food industry, the demand for natural antioxidants is increasing mainly due to the questionable safety of synthetic antioxidant compounds that are related to their possible toxic effects when considering long-term intake. Besides, consumers prefer to select natural antioxidants in their products, which are considered safer and healthier [4].

Several studies have showed that lignin can serve as a renewable source of aromatic compounds with antioxidant capacity [5-10]. However, the antioxidant capacity of lignins, as well as their physicochemical properties, significantly depends on the source of lignocellulosic

\footnotetext{
* Corresponding author.

E-mail address: mimichelin.bio@gmail.com (M. Michelin).
}

material and extraction method employed. Nevertheless, the differences between lignin from various plant sources are reported to be minor when compared to the differences that can be observed from different pretreatments [11,12].

Organosolv is an interesting process able to produce a high purity (low inorganic impurities and sulfur-free) and low molecular weight (Mw) lignin, offering new possibilities for high quality applications, and recovers a solid residue rich in cellulose, which is also suitable for enzymatic saccharification [12,13]. For some LCMs the combination of hydrothermal pretreatment and organosolv can be used to increase the effective fractionation of the materials [12]. Currently, liquid hot water (also known as autohydrolysis) has been used prior the organosolv process to selectively remove hemicelluloses and obtain cellulose and lignin [6,13-16]. Under this process, lignin can be degraded or de-polymerized into small molecular fragments, which need to be fully characterized in order to be applied as bio-based chemicals and materials $[16,17]$.

However, the works that explored the integrated process focused mainly on the structural characterization of lignin [16,18,19], or only described the study of extraction of lignin, sometimes added of the enzymatic hydrolysis of the cellulose fraction [13-15,20]. Still, there are few studies, involving the integrated process, that have explored the biological properties of lignin, such as antioxidant activity [6,21]. In 
addition, all of these works have not successful achieved the complete removal of hemicellulose during hydrothermal pretreatment. Therefore, the present study presents an integrated fractionation of LCMs from corncob using a liquid hot water (LHW) step for the complete removal of hemicelluloses, and ethanol organosolv (EO) for the separation of cellulose and lignin. The EO conditions were evaluated using an experimental design ( $2^{3}$ with a central point) and the lignins obtained were characterized regarding their in vitro antioxidant activity, total phenolics, structural features (FTIR) and thermal properties (TGA and DSC). These lignin samples were also compared with the lignin from the direct EO process.

\section{Materials and methods}

\subsection{Materials}

Corncob (CC) was supplied by a local farmer (Ponte da Barca, Northern Portugal). This feedstock was dried at $40{ }^{\circ} \mathrm{C}$ for $12 \mathrm{~h}$. After that, it was milled and sieved to obtain particles sizes from 1 to $2.5 \mathrm{~mm}$ (Retsch SM 2000 cutting mill, Germany), and stored at room temperature.

The chemicals 2,2 diphenyl 1 picrylhydrazyl (DPPH), 2,2' azino bis ( 3 ethylbenzothiazoline 6 sulphonic acid) (ABTS), 6 hydroxy 2,5,7,8 tetramethylchroman 2 carboxylic acid (Trolox), butylated hydroxytoluene (BHT) and butylated hydroxyanisole (BHA), Folin-Ciocalteu reagent and gallic acid were purchased from SigmaAldrich. Ethanol was obtained from Panreac (Spain).

\subsection{Extraction of lignin}

A two-step pretreatment, involving LHW and EO, was applied to corncob in an integrated process in order to extract the lignin. Lignin from the direct EO process was used as control to compare the effectiveness of the integrated process.

\subsubsection{Liquid hot water pretreatment}

LHW pretreatment condition was selected based on previous results obtained in a study of hydrothermal pretreatment [22]. Untreated corncob was mixed with distilled water at solid loading of $10 \%(\mathrm{w} / \mathrm{v})$ in a 2.0 L stainless steel cylindrical reactor (Parr Instruments Company, Moline Illinois, USA) equipped with a Parr PID temperature controller (model 4848). The reaction media was stirred at $150 \mathrm{rpm}$ and heated by an external jacket until a final temperature of $200{ }^{\circ} \mathrm{C}$ that was maintained for $30 \mathrm{~min}$ (these conditions correspond to a $\log R_{0}=4.42$ ). After that, the reactor was rapidly cooled-down through water recirculation by an internal loop.

The insoluble solids were separated from the liquid fraction (slurry) by filtration using Whatman ${ }^{\circledR} \mathrm{N}^{\circ} 1$ filter paper. These were washed with distilled water at $70{ }^{\circ} \mathrm{C}$ and dried at $50{ }^{\circ} \mathrm{C}$. The hydrolysate obtained in the filtrate by the liquid hot water process was used to determine the compounds derived from hemicellulose, by-products and soluble lignin.

\subsubsection{Organosolv process}

The EO of the LHW-pretreated and untreated corncobs was carried out using a solid loading of $10 \%(\mathrm{w} / \mathrm{v})$ in $160 \mathrm{~mL}$ stainless steel cylindrical reactors ( $4.0 \mathrm{~cm}$ internal diameter and $12.4 \mathrm{~cm}$ internal height), with a working volume of $50 \mathrm{~mL}$. LHW-pretreated corncob was delignified using uncatalyzed ethanol-water solutions according to the DOE described in the next section. Untreated corncob was delignified in the optimal organosolv condition. The reactors were submerged into the oil bath with an open heating circulator (Julabo Labortechnik $\mathrm{GmbH}$, Seelbath, Germany) and PID temperature control at the desired temperature. After the reaction time, the reactors were cooled in an ice bath to stop the reaction.

The hydrothermally pretreated ethanol organosolv residue (HPEOR) and the ethanol organosolv residue (EOR) were obtained by filtration using Whatman ${ }^{\circledR} \mathrm{N}^{\circ} 1$ filter paper. These were washed with ethanol (at the same concentration of the pretreatment) to remove any adsorbed lignin on the cellulosic fibers. Afterwards, the solid residues were washed with distilled water at $70{ }^{\circ} \mathrm{C}$ until a neutral $\mathrm{pH}$ was obtained. Finally, this material was dried at $100{ }^{\circ} \mathrm{C}$, and the yields of organosolv process were determined by weight. The liquid fraction was combined with the ethanol washing volume and the lignin (hydrothermally pretreated ethanol organosolv lignin (HP-EOL) and ethanol organosolv lignin (EOL)) was recovered through solvent evaporation.

The yield of lignin or solid residue was determined according to Eq. (1).

Yield $(\%)=\left(\frac{m_{\text {recovered }}}{m_{\text {corncob }}}\right) \times 100$

where $m_{\text {recovered }}$ is the mass of lignin or solid residue recovered after the pretreatment $(\mathrm{g}), m_{\text {corncob }}$ is the mass of the crude corncob used for the pretreatment $(\mathrm{g})$.

The lignin extraction efficiency was determined according to Eq. (2).

Extraction efficiency $(\%)=\left(\frac{m_{\text {recovered }}}{K L_{\text {corncob }}}\right) \times 100$

where $m_{\text {recovered }}$ is the mass of lignin recovered after the pretreatment (g) and $K L_{\text {corncob }}$ is the mass of Klason lignin in the crude corncob (g).

The delignification extent was determined by Eq. (3), according to Novo et al. [23].

Delignification (\%) $=\left(\frac{K L_{\text {corncob }}-\left(K L_{\text {pulp }} \frac{Y_{\text {pulp }}}{100}\right)}{K L_{\text {corncob }}}\right) \times 100$

where $K L_{\text {corncob }}$ is the quantity of Klason lignin in the corncob (\%), $K L_{\text {pulp }}$ is the quantity of the Klason lignin in the pulp (\%) and $Y_{p u l p}$ is the yield of the pulping reaction (\%).

\subsubsection{Design of experiments}

The organosolv experiments were performed using a design of experiments (DOE) as a tool to evaluate the effect of temperature $(T)$, time $(t)$, and ethanol (EtOH) content on lignin extraction of the LHWpretreated corncob.

The DOE used was a cubic experimental design procedure with three factors of two levels each $\left(2^{3}\right)$ and using the central point for error evaluation. The independent variables were temperature $\left({ }^{\circ} \mathrm{C}\right),[140(-1)$, $160(0), 180(+1)]$, time (min), [40(-1), 80(0), 120(+1)], and ethanol concentration (\%), [20(-1), 40(0), 60(+1)]. The analyzed responses (dependent variables) were: solid residue and lignin yields, chemical composition, delignification percentage and lignin extraction efficiency. The results were assessed by Pareto diagram with STATISTICA 8.0 (Stat Soft Inc., USA) to verify the factors displaying a significance higher than $5 \%$.

\subsection{Analysis of raw and pretreated corncob}

Aliquots of the solid material (untreated and pretreated feedstocks) were milled to a particle size $<0.5 \mathrm{~mm}$ and subjected to chemical composition analyses according to the standard Laboratory Analytical Procedures (LAPs) for biomass analysis provided by the US National Renewable Energy Laboratory (NREL) [24]. All measurements were made in duplicate. Analyzed components were glucan, xylan, arabinan, acetyl groups, lignin, and ash. The protein content was calculated based on the nitrogen content estimated by the Kjeldahl method, multiplied by a factor of 6.25 . The liquor from pretreated materials was analyzed for monomeric sugars, acetic acid, oligomeric sugars, acetyl groups and degradation products (hydroxymethylfurfural (HMF) and furfural). The oligomeric sugars were calculated after a quantitative posthydrolysis 
with $4 \%$ sulfuric acid at $121^{\circ} \mathrm{C}$, during $60 \mathrm{~min}$. The increase of monosaccharide (glucose, xylose and arabinose) and acetic acid concentrations caused by posthydrolysis provided a measure of the concentrations of oligomers and acetyl groups bound to oligosaccharides [25]. The monosaccharaides, organic acids and degradation products were determined by HPLC (JASCO Intelligent Sampler AS 2057 Plus) through a Metacarb $87 \mathrm{H}$ column $(300 \times 7.8 \mathrm{~mm}$, Varian, USA). The mobile phase was $0.005 \mathrm{M} \mathrm{H}_{2} \mathrm{SO}_{4}$ in Milli-Q water, pumped at a flow rate of $0.6 \mathrm{~mL} \cdot \mathrm{min}^{-1}$, at $60{ }^{\circ} \mathrm{C}$. Sugars and acetic acid were analyzed with a refractive index (RI) detector and furfural and HMF with a UV detector.

\subsection{Total phenolic content}

Total phenolic content was estimated by the Folin-Ciocalteu colorimetric method, based on the procedure of Makkar et al. [26], using gallic acid as a standard phenolic compound. The absorbance at $725 \mathrm{~nm}$ was evaluated using glass cuvettes. The total phenolic content was expressed as Gallic Acid Equivalents (GAE) in milligrams per gram by means of a calibration curve obtained with a standard of gallic acid.

\subsection{Antioxidant activity}

Lignin antioxidant capacity was studied by evaluating free radical scavenging effect through ABTS and DPPH methods that are common spectrophotometric procedures for determining the antioxidant capacities of components.

\subsubsection{DPPH free radical scavenging activity}

The DPPH radical scavenging activities of lignins (HP-EOL and EOL) were measured according to the slightly modified method of Blois [27]. Trolox, butylated hydroxytoluene (BHT) and butylated hydroxyanisole (BHA) were utilized as reference.

A $150 \mathrm{mM}$ of DPPH solution was prepared in $80 \%$ ethanol and diluted to get an absorbance of 0.700 at $517 \mathrm{~nm}$. Lignin samples were dissolved in $80 \%$ ethanol at concentrations from $0.05 \mathrm{mg} / \mathrm{mL}$ to $1 \mathrm{mg} / \mathrm{mL}$ and a volume of $25 \mu \mathrm{L}$ was mixed with $200 \mu \mathrm{L}$ of DPPH solution. These samples were incubated for $30 \mathrm{~min}$ at room temperature in dark. The decrease of the absorbance was measured using a UV-Vis spectrophotometer against a control sample ( $25 \mu \mathrm{L}$ of $80 \%$ ethanol plus $200 \mu \mathrm{L}$ of DPPH solution).

The percentage of radical scavenging activity (RSA) was calculated using the Eq. (4):

$\operatorname{RSA}(\%)=\left[\frac{\left(A_{\text {control }}-A_{\text {sample })}\right.}{A_{\text {control }}}\right] \times 100$

where $A_{\text {control }}$ is the absorbance of the control sample and $A_{\text {sample }}$ is the absorbance of the lignin sample.

The $\mathrm{IC}_{50}$ value was also calculated as the concentration of the compounds that causes $50 \%$ reduction in the DPPH color (also referred as inhibition). All experiments were carried out in duplicate.

\subsubsection{ABTS radical scavenging activity}

The ABTS radical scavenging activity of lignins (LHW-EOL and EOL) was determined according to the method of Re et al. [28], which is based on the ability of antioxidants to interact with the ABTS radical, decreasing its absorbance at $734 \mathrm{~nm}$. Trolox, BHT and BHA were utilized as reference. The ABTS stock solution ( $7 \mathrm{mM}$ ABTS and $2.45 \mathrm{mM}$ potassium persulfate in ultrapure water, ratio of 1:1) was prepared and kept in the dark at room-temperature for 12-16 h before using. Before being used, the ABTS solution was diluted with ultra-pure water to get an absorbance of 0.700 at $734 \mathrm{~nm}$. For the analysis, $100 \mu \mathrm{L}$ of the diluted ABTS solution were mixed with $100 \mu \mathrm{L}$ of the lignin sample dissolved in ethanol $60 \%$ at different concentrations $(0.005-0.1 \mathrm{mg} / \mathrm{mL})$. After 6 min the absorbance was measured and the percentage inhibition was calculated for each concentration against a blank sample ( $100 \mu \mathrm{L}$ of diluted ABTS mixed with $100 \mu \mathrm{L}$ of ultrapure water). The percentage of RSA was calculated as described previously.

\subsection{Attenuated total reflectance - Fourier transform infrared spectroscopy (ATR-FTIR)}

The ATR-FTIR spectra were obtained on a spectrophotometer model FT/IR-4100 type A (Origin, Jasco) of direct transmittance on the solid sample. Samples were analyzed from 4000 to $600 \mathrm{~cm}^{-1}$ at a resolution of $4 \mathrm{~cm}^{-1}$ and 16 scans were recorded.

\subsection{Thermogravimetric analysis (TGA)}

Thermal degradation behavior of the lignin samples was determined by TGA using a thermogravimetric analyzer 4000 (Perkin Elmer, Waltham, Massachusetts, EUA) and a nitrogen atmosphere. Samples with approximately $10 \mathrm{mg}$ of material were heated from $20^{\circ} \mathrm{C}$ up to $800{ }^{\circ} \mathrm{C}$ at a rate of $10^{\circ} \mathrm{C} / \mathrm{min}$. Analyzes were performed in duplicate.

\subsection{Differential scanning calorimetry analysis (DSC)}

The glass transition temperature was measured using a DSC analyzer 6000 (Perkin Elmer, Waltham, Massachusetts, EUA). Approximately $5 \mathrm{mg}$ of sample was placed into aluminium pans, sealed with the aluminium covers (Perkin-Elmer, DSC, B0143016/B0143003, respectively) and heated between 0 and $200{ }^{\circ} \mathrm{C}$ at a scanning speed of $10{ }^{\circ} \mathrm{C} / \mathrm{min}$ in a nitrogen atmosphere using a refrigerating cooling accessory. An empty aluminium pan was used as reference. Glass transition was calculated by using a half-height technique in the transition region. Calibration was performed using an indium sample. Analyzes were performed in duplicate.

\section{Results and discussion}

Corncob was subjected to the integrated process based on liquid hot water and ethanol organosolv process (Fig. 1). The main products obtained from the process included lignin, cellulose and compounds derived from hemicellulose. The next two subsections describe the chemical composition and yield of the pretreated corncob obtained with the integrated process and the organosolv process, as well as the crude corncob.

\subsection{Chemical composition of the raw and LHW-pretreated corncob}

The chemical composition of untreated and LHW-pretreated corncob is presented in Table 1 . Corncob is mainly composed by cellulose $(\approx 36 \%)$, hemicellulose $(\approx 31 \%)$ and lignin $(\approx 21 \%)$ and its composition was similar to the ones previously reported by other authors [22,29-32].

The LHW pretreatment condition was established based on previous results [22], which showed the effect of temperature and residence time of LHW-pretreatment on hemicellulose-derived products' solubilization, such as XOS, xylose and furfural, as well as on the recovery of cellulose and lignin from corncob. In the current study, the selected condition was $200{ }^{\circ} \mathrm{C}$ and $30 \mathrm{~min}$. Under this condition, $51 \%$ of spent solid was recovered and all hemicellulose (30.5\%) was solubilized in the hydrolysate mainly as free xylose $(5.7 \mathrm{~g} / \mathrm{L})$ and furfural $(7.7 \mathrm{~g} / \mathrm{L})$. The hemicellulose removal increased the cellulose and lignin contents in pretreated corncob through a concentration effect (Table 1). The content in cellulose, expressed as glucan, increased from $35.8 \%$ to $60.4 \%$ in the pretreated material, whereas the lignin content (Klason lignin and acid-soluble lignin) increased from $20.7 \%$ to $34.8 \%$. Delignification $(6.56 \%)$ is low due to the limited solubility of lignin in acid medium, which is caused by the solubilization of acetic acid from hemicellulose [33,34]. 


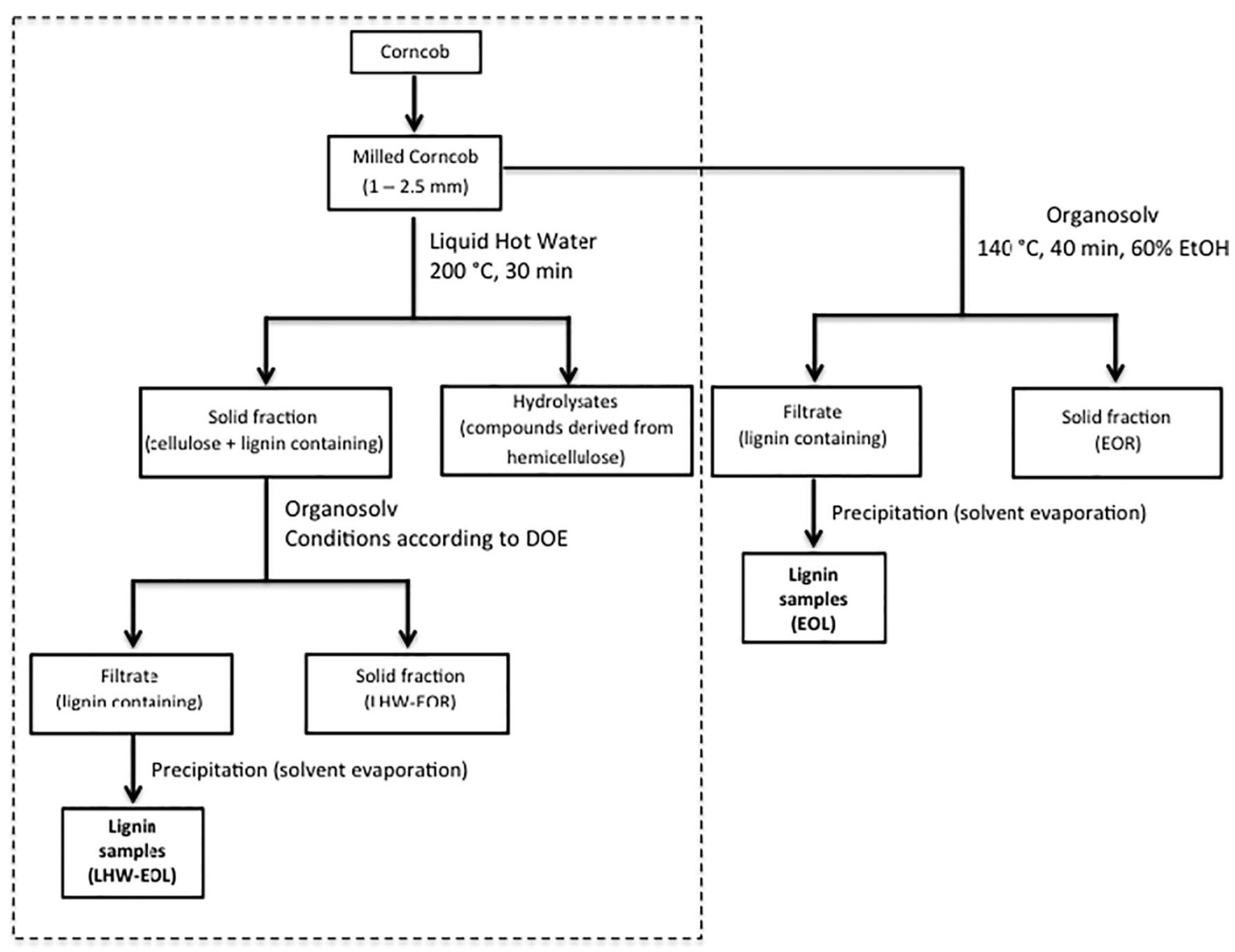

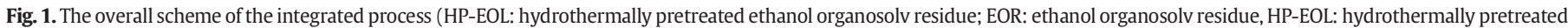
ethanol organosolv lignin; EOL: ethanol organosolv lignin).

Table 1

Chemical composition of raw and LHW-pretreated corncob, expressed as percentage on a dry weight basis and reported as average values ( \pm standard deviation).

\begin{tabular}{|c|c|c|}
\hline Components & $\begin{array}{l}\text { Raw corncob } \\
\%(w / w)\end{array}$ & $\begin{array}{l}\text { LHW-pretreated corncob } \\
\%(\mathrm{w} / \mathrm{w})\end{array}$ \\
\hline \multicolumn{3}{|l|}{ Solids (\%) } \\
\hline Cellulose $^{a}$ & $35.84 \pm 0.01$ & $60.42 \pm 0.85$ \\
\hline \multicolumn{3}{|l|}{ Hemicellulose } \\
\hline Xylan & $22.51 \pm 1.62$ & n.d. \\
\hline Arabinan & $5.60 \pm 0.01$ & n.d. \\
\hline Acetyl group & $2.42 \pm 0.21$ & n.d. \\
\hline \multicolumn{3}{|l|}{ Lignin } \\
\hline Klason lignin & $18.00 \pm 0.98$ & $32.98 \pm 0.22$ \\
\hline Soluble lignin & $2.66 \pm 0.20$ & $1.82 \pm 0.04$ \\
\hline Ashes & $7.70 \pm 0.30$ & $0.78 \pm 0.10$ \\
\hline Protein & $3.46 \pm 0.01$ & \\
\hline \multicolumn{3}{|l|}{ Hydrolysates (g/L) } \\
\hline \multicolumn{3}{|l|}{ Oligosaccharides } \\
\hline Gluco-oligosaccharides & & $1.24 \pm 0.05$ \\
\hline Xylo-oligosaccharides & & n.d. \\
\hline Arabino-oligosaccharides & & n.d. \\
\hline Acetyl groups-oligosaccharides & & n.d. \\
\hline \multicolumn{3}{|l|}{ Monosaccharides } \\
\hline Glucose & & $1.32 \pm 0.05$ \\
\hline Xylose & & $5.65 \pm 0.29$ \\
\hline Arabinose & & $1.63 \pm 0.11$ \\
\hline Acetic acid & & $4.81 \pm 0.23$ \\
\hline \multicolumn{3}{|l|}{ Degradation products } \\
\hline Hydroxymethylfurfural & & $0.53 \pm 0.01$ \\
\hline Furfural & & $7.69 \pm 0.06$ \\
\hline
\end{tabular}

n.d.: not detected.

a Estimated from glucan content.
Gurgel et al. [20] have reported that soluble lignin tends to condensate in acid-catalyzed reactions, such as autocatalyzed pretreatments with longer times, leading to a more condensed lignin in the solid fraction. In addition, it has also been suggested that dissolved lignin-derived products with high molecular mass precipitate on the surface of the lignocellulosic residue during reactor cooling. Their results also showed increased glucan (from $43.43 \%$ to $66.53 \%$ ) and lignin (from $22.00 \%$ to $30.02 \%$ ) contents in the LHW-pretreated material, and a residual of hemicellulose in the solid fraction. Overall, delignification in LHW at $180{ }^{\circ} \mathrm{C}$ for 20 min reached $12.83 \%$.

Romaní et al. [14] have also reported that increasing severity (So) and/or temperature results in lignin repolymerization. Therefore, the longer pretreatment time of our work may have led to more condensed lignin in the solid fraction and, consequently, to less delignification. The lower delignification in our work is interesting because the aim in this step (LHW pretreatment) was removing hemicellulose, that was successfully achieved, while preserving the cellulose and lignin fractions to be separated in the next step (organosolv pretreatment).

Ruiz et al. [15] reported a similar effect of autohydrolysis in wheat straw residue. Cellulose and lignin contents increased from $37.4 \%$ to $63.7 \%$ and 19.4 to $26.9 \%$, respectively, due to the hemicellulose removal. However, unlike our work, not all hemicellulose has been removed, with $7.8 \%$ of the $33.8 \%$ of the raw material remaining at the end of the process. Romaní et al. [14] reported contents of cellulose and lignin for Eucalyptus globulus wood samples in the ranges 54.3-61.4\% and 26.3-32.0\%, respectively, after autohydrolysis. However, a small hemicellulose fraction also remained in the solid fraction (2.7-10.9\%) and xylooligomers were the major hemicellulose-derived soluble components, with minor amounts of xylose and furfural.

Zhu et al. [16] reported that cellulose content increased from $42.7 \%$ to $54.1 \%$ after an autohydrolysis process, whereas the content of 
hemicelluloses decreased from $19.8 \%$ to $3.2 \%$, to form XOS and other byproducts. In that work, the autohydrolysis also resulted in an increase of the content of lignin (Klason lignin and acid-soluble lignin) from $21.1 \%$ (dewaxed residue) to $31.5 \%$ (hydrothermally treated residue). Finally, Wen et al. [18] studied bamboo culm. The carbohydrate analysis revealed that glucan $(40.1 \%)$ and xylan $(29.0 \%)$ were the dominant constituents in crude bamboo, while arabinans are only present in minor amounts. Lignin content was $26.7 \%$. After autohydrolysis, the glucan and lignin contents increased to $53.0 \%$ and $37.0 \%$, respectively, while the content of xylan decreased to $8.8 \%$.

Therefore, the LHW condition of our work allowed a complete hemicellulose removal and good preservation of cellulose and lignin in the solid fraction to be treated in the next step.

\subsection{Extraction of lignin}

The spent solid recovered from LHW was submitted to an EO, where different variables were studied according to an experimental design. The results showed a significant delignification (around 57-62\%) with a good glucan preservation (83-89\%) for the solid residues (or cellulose pulp) of the samples 2, 4, 6 and 8 (Table 2). The high glucan contents of these solids are an advantage for their use as potential substrates for biofuel production after enzymatic hydrolysis. Under these conditions, the lowest amount of residual Klason lignin (around 15-17\%) was observed. It is important to note that higher values of cellulose content on solid residues were attained for the highest ethanol concentrations $(60 \%, v / v)$.

Regarding lignin (liquid samples), most of it was depolymerized and removed after the EO process. Maximum delignification of LHWpretreated corncob (obtained for samples 2, 4, 6 and 8) led to a solubilization (lignin yield) of 16.7 to $18 \%$ of lignin (relative to the LHW-solids mass), that was recovered by precipitation (Table 3). Under these conditions, high purity lignin was recovered (lignin content of 87-93\%), with an extraction efficiency between 50.6 and 54.6\%.

Results showed that the extraction yield and the efficiency of extraction of lignin, as well as the yield and delignification of cellulose pulp, were significantly affected by ethanol concentration $(p<0.05)$. Therefore, the best compromise between lignin removal and cellulose preservation was obtained at a high ethanol concentration. This effect is supported by Pareto charts (Fig. 2) drawn from the experimental design. In the case of delignification (Fig. 2B), temperature $(T)$ is also affecting the results.

Romaní et al. [14] recovered a solid phase from the integrated process of autohydrolysis and EO containing $70.3-86.9 \%$ cellulose and 10.2-22.7\% lignin. However, a value ranging between 3.0 and $8.3 \%$ of xylan remained in the solid fraction, since autohydrolysis did not solubilize all hemicellulose, as mentioned previously. The authors also observed that higher severities (So and/or temperature) improved delignification up to a minimum of $10.2 \%$ of lignin in the solid residue, and that increasing So and/or temperature beyond these limits resulted in increased lignin, a fact ascribed to lignin repolymerization. Although Romaní et al. [14] reported a slightly smaller lignin content in the solid fraction, a small content of hemicellulose still remained in these fractions. Furthermore, no indicative of repolimerization of lignin was observed in our work under the studied organosolv conditions, that indicates that delignification can be improved. Ruiz et al. [15] also used the integrated process of autohydrolysis and EO (using $0.1 \%$ (w/ v) $\mathrm{NaOH}$ as catalyst) and recovered solids with $75.9 \%$ cellulose, $16.2 \%$ lignin and $6.6 \%$ of residual hemicellulose. Therefore, even using a catalyst, a significant amount of lignin and hemicellulose remained in the solids, compared with our work.

An et al. [35] obtained similar yields (13.4-22.5\%) for three lignin fractions obtained from a residue pretreated by steam explosion and enzymatic hydrolysis, and that was purified using a dioxane extraction process and dichloromethane fractionation. However, the concentration of Klason lignin in these fractions was lowered (73.6-83.7\%), and showed a small carbohydrate content (6.6-14.1\%) derived from hemicellulose and cellulose.

In order to evaluate the effect of LHW in the process, EO was applied to the crude corncob without using the hydrothermal process. Since the ethanol concentration was the main parameter that affected the evaluated responses, this variable was maximized for the new experiment, using the lowest temperature and time and thus reducing the extraction costs and making the process economically more feasible. So, the EO process of the crude corncob was performed at $140{ }^{\circ} \mathrm{C}, 40 \mathrm{~min}$ and $60 \%$ ethanol.

Organosolv applied to crude corncob recovered a solid residue (EOR) containing $51.47 \%$ cellulose, $31.86 \%$ hemicellulose, and $11.61 \%$ of residual Klason lignin. Therefore, mainly lignin was extracted from solids according to the chemical composition of the crude corncob. The delignification degree (42.26\%) and the solid yield (89.52\%) were similar to some samples from HP-EOR (except for samples 2, 4, 6 and 8). Regarding the EOL solubilized into the solvent, the lignin extraction yield was $10.48 \%$, i.e. similar to some HP-EOL samples (except for samples 2, 4, 6 and 8). However, the extraction efficiency (58.22\%) was as high as HP-EOL 2, 4, 6 and 8 samples, that were recovered by using high ethanol concentration. The solubilized lignin contained $10.32 \%$ of carbohydrates, while the lignin content (approx. 55\%) was lower than HP-EOR (87-93\%). In the LHW pretreatment the hemicellulose fraction of the corncob is removed, which makes the resulting lignocellulosic biomass

Table 2

Chemical composition of residual solids after delignification of the LHW-pretreated corncob.

\begin{tabular}{|c|c|c|c|c|c|c|c|}
\hline \multirow[t]{2}{*}{ Sample } & \multicolumn{3}{|c|}{ Organosolv process conditions } & \multicolumn{4}{|c|}{ Results organosolv process } \\
\hline & $\mathrm{T}\left({ }^{\circ} \mathrm{C}\right)^{\mathrm{a}}$ & $\mathrm{t}(\min )^{\mathrm{a}}$ & $\mathrm{EtOH}(\%)^{\mathrm{a}}$ & Solid residue yield (\%) & Cellulose $(\%)^{\mathrm{b}}$ & Residual lignin $(\%)^{\mathrm{c}}$ & $\mathrm{D}(\%)^{\mathrm{d}}$ \\
\hline 1 & $140(-1)$ & $40(-1)$ & $20(-1)$ & 93.77 & $75.66 \pm 2.46$ & $23.43 \pm 2.05$ & 33.38 \\
\hline 2 & $140(-1)$ & $40(-1)$ & $60(+1)$ & 82.52 & $82.72 \pm 0.96$ & $17.21 \pm 1.76$ & 56.94 \\
\hline 3 & $140(-1)$ & $120(+1)$ & $20(-1)$ & 93.70 & $76.99 \pm 3.27$ & $22.67 \pm 2.10$ & 35.59 \\
\hline 4 & $140(-1)$ & $120(+1)$ & $60(+1)$ & 83.30 & $83.00 \pm 3.00$ & $16.73 \pm 1.21$ & 57.74 \\
\hline 5 & $180(+1)$ & $40(-1)$ & $20(-1)$ & 92.35 & $74.46 \pm 0.76$ & $21.29 \pm 0.34$ & 40.38 \\
\hline 6 & $180(+1)$ & $40(-1)$ & $60(+1)$ & 81.99 & $82.53 \pm 0.64$ & $15.37 \pm 1.34$ & 61.79 \\
\hline 7 & $180(+1)$ & $120(+1)$ & $20(-1)$ & 91.93 & $74.54 \pm 1.50$ & $22.51 \pm 0.59$ & 37.25 \\
\hline 8 & $180(+1)$ & $120(+1)$ & $60(+1)$ & 82.19 & $88.62 \pm 2.04$ & $15.82 \pm 0.20$ & 60.57 \\
\hline 9 & $160(0)$ & $80(0)$ & $40(0)$ & 89.59 & $78.95 \pm 2.50$ & $19.82 \pm 2.99$ & 46.16 \\
\hline 10 & $160(0)$ & $80(0)$ & $40(0)$ & 89.63 & $77.69 \pm 1.90$ & $19.94 \pm 3.78$ & 45.81 \\
\hline 11 & $160(0)$ & $80(0)$ & $40(0)$ & 89.23 & $77.89 \pm 2.85$ & $19.71 \pm 3.49$ & 46.67 \\
\hline EOL & $140(-1)$ & $40(-1)$ & $60(+1)$ & 89.52 & $51.47 \pm 3.50$ & $11.61 \pm 0.10$ & 42.26 \\
\hline
\end{tabular}

n.d.: not detected.

a Value of coded variable levels in parenthesis.

b Estimated from glucan content.

c Acid insoluble lignin.

d D: delignification. 
Table 3

Chemical composition of precipitated lignin after organosolv process of the LHW-pretreated corncob.

\begin{tabular}{|c|c|c|c|c|c|c|c|}
\hline \multirow[t]{2}{*}{ Sample } & \multicolumn{3}{|c|}{ Organosolv process conditions } & \multicolumn{4}{|c|}{ Results organosolv process } \\
\hline & $\mathrm{T}\left({ }^{\circ} \mathrm{C}\right)^{\mathrm{a}}$ & $\mathrm{t}(\min )^{\mathrm{a}}$ & $\mathrm{EtOH}(\%)^{\mathrm{a}}$ & Lignin yield $(\%)^{\mathrm{b}}$ & Lignin $(\%)^{c}$ & Carbohydrate (\%) ${ }^{\mathrm{d}}$ & Extraction efficiency (\%) \\
\hline 1 & $140(-1)$ & $40(-1)$ & $20(-1)$ & 6.23 & $79.44 \pm 2.46$ & n.d. & 18.88 \\
\hline 2 & $140(-1)$ & $40(-1)$ & $60(+1)$ & 17.48 & $91.79 \pm 0.19$ & n.d. & 53.00 \\
\hline 3 & $140(-1)$ & $120(+1)$ & $20(-1)$ & 6.3 & $80.84 \pm 3.27$ & n.d. & 19.11 \\
\hline 4 & $140(-1)$ & $120(+1)$ & $60(+1)$ & 16.7 & $87.15 \pm 3.00$ & n.d. & 50.62 \\
\hline 5 & $180(+1)$ & $40(-1)$ & $20(-1)$ & 7.65 & $78.18 \pm 0.76$ & $1.66 \pm 0.34$ & 23.21 \\
\hline 6 & $180(+1)$ & $40(-1)$ & $60(+1)$ & 18.01 & $86.66 \pm 0.64$ & $1.66 \pm 1.34$ & 54.61 \\
\hline 7 & $180(+1)$ & $120(+1)$ & $20(-1)$ & 8.07 & $78.27 \pm 1.50$ & $2.22 \pm 0.59$ & 24.46 \\
\hline 8 & $180(+1)$ & $120(+1)$ & $60(+1)$ & 17.81 & $93.05 \pm 2.04$ & n.d. & 53.99 \\
\hline 9 & $160(0)$ & $80(0)$ & $40(0)$ & 10.41 & $82.90 \pm 2.50$ & n.d. & 31.56 \\
\hline 10 & $160(0)$ & $80(0)$ & $40(0)$ & 10.37 & $81.57 \pm 1.90$ & n.d. & 31.43 \\
\hline 11 & $160(0)$ & $80(0)$ & $40(0)$ & 10.77 & $81.78 \pm 2.85$ & n.d. & 32.64 \\
\hline EOL & $140(-1)$ & $40(-1)$ & $60(+1)$ & 10.48 & $54.90 \pm 11.18$ & $10.51 \pm 0.10$ & 58.22 \\
\hline
\end{tabular}

n.d.: not detected.

a Value of coded variable levels in parenthesis.

b Calculated by difference.

c Acid insoluble lignin.

d Only glucose was detected, with exception of EOL

more accessible for delignifying solvents at mild conditions. However, in case of direct delignification, a certain pretreatment severity is required to remove hemicellulose before an effective delignification can occur.

Therefore, these results proved the effectiveness of an integrated process, mainly because the LHW process promoted the solubilization of hemicelluloses and cleavage of lignin-carbohydrate, improving lignin extraction and cellulose-rich residue preservation. Wen et al. [18] recovered lignin by an integrated process (hydrothermal treatment plus organosolv, HT-OL) and obtained an extraction efficiency of $62.2 \%$ (mentioned by the authors as lignin yield based on the Klason lignin), which was higher than the direct OL (31.5\%), showing the advantages of the integrated process. After the organosolv process, glucan content on the solid residue significantly increased to $73.2 \%$. However, if the organosolv process was directly applied to residue without autohydrolysis, the content of glucan increased slightly to $44.6 \%$, while almost all xylan remained on solids, showing again advantage of the integrated process. Regarding the residual lignin on pretreated solids, if direct organosolv was applied to raw material, $21.7 \%$ from $26.7 \%$ of Klason lignin still remained in the pretreated material. However, if autohydrolysis was applied to residue prior to organosolv process, only $12.1 \%$ of Klason lignin was found in the pretreated material. According to the lignin yield obtained, it was found that autohydrolysis improved the organosolv process enhancing the delignification and recovering most of lignin (62.2\%). Instead, the direct organosolv process recovered only a smaller part of lignin (31.5\%).

Gurgel et al. [20] reported a significant delignification $(\approx 82.46 \%)$ with a good preservation of glucan $(\approx 84.58 \%)$ with the delignification of the LHW pretreated sugarcane bagasse (SCB) at $140{ }^{\circ} \mathrm{C}$ for $45 \mathrm{~min}$. They compared their results to that reported by Pasquini et al. [36],
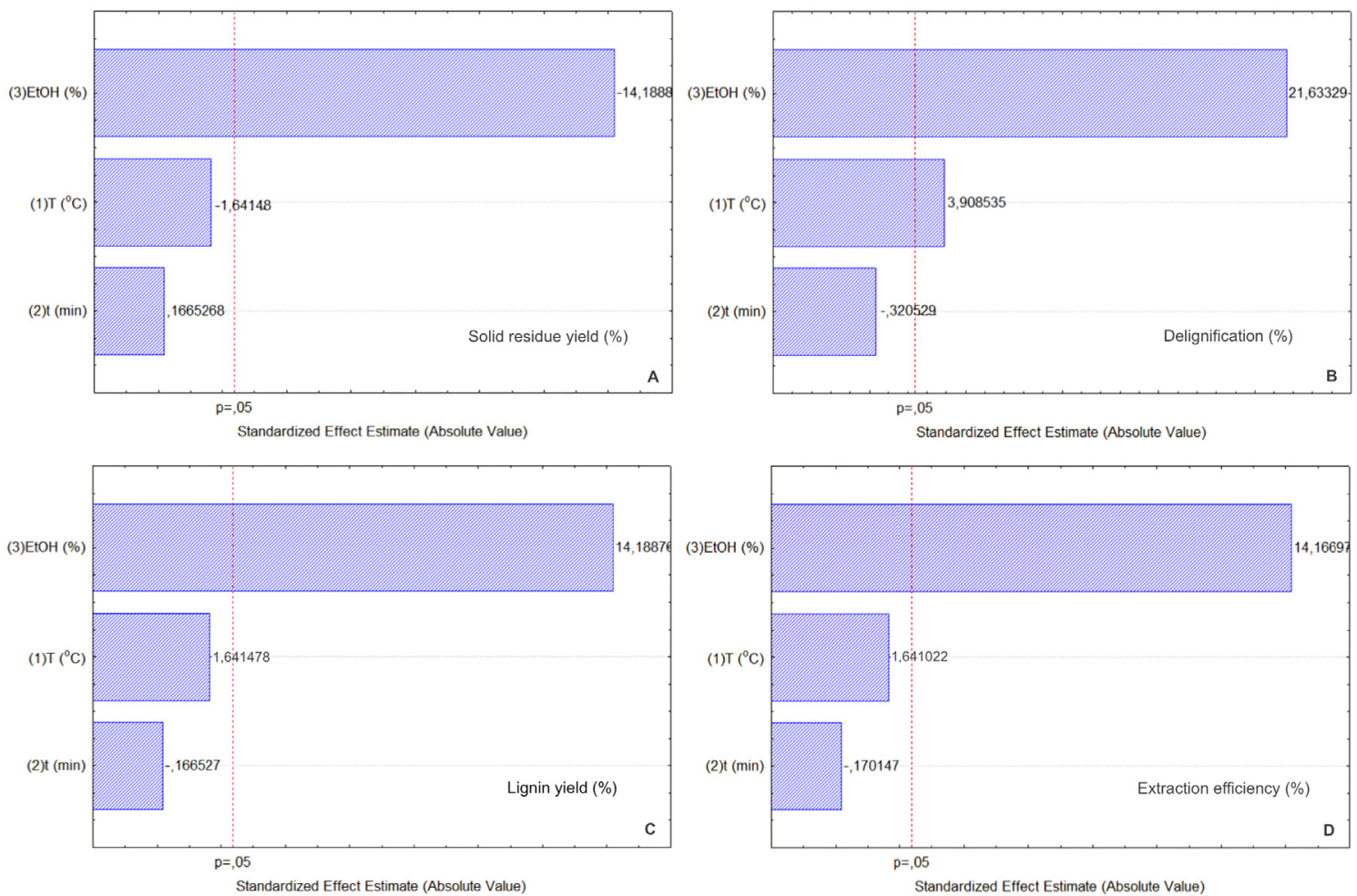

Fig. 2. Pareto diagrams of the responses from the cubic experimental design $\left(2^{3}\right)$. T denotes the temperature, $t$ the time and EtOH the ethanol concentration. 
which studied the delignification of untreated SCB, and concluded that LHW pretreated SCB presented higher delignification at a lower temperature and a shorter reaction time than unpretreated SCB. This result shows the impact of LHW pretreatment conditions on the structure of lignin. In general, the results reported by other authors were similar to those of the present work, with the advantage of the complete removal of hemicellulose in our work.

\subsection{Total phenolic content and antioxidant activities of lignins}

Phenolic hydroxyl groups of lignin are the main responsible for its antioxidant activity [35]. The presence of phenolics and antioxidant activity can be evaluated by the total phenolic content and the DPPH and ABTS methods.

The total phenolic content of the HP-EOL samples was highly influenced by ethanol concentration, increasing for higher ethanol concentrations. This was the only condition tested that statistically influenced the total phenolic content values $(p<0.05)$. Ethanol leads to the depolymerization of lignin structure, that in turn enhances its solubilization into the solvent and the formation of new phenolic hydroxyl groups. Among all HP-EOL samples, samples 2, 4, 6 and 8 showed the highest total phenolic content which was up to $25.6 \mathrm{mg} \mathrm{GAE} / \mathrm{g}$, indicating that the total phenolic content of lignin was remarkably improved by ethanol concentration $(60 \% \mathrm{w} / \mathrm{v})$. Qazi et al. [37] reported total phenolic content values of pyrolytic Kraft lignins between 0.42 and $50 \mathrm{mg} \mathrm{GAE} / \mathrm{g}$. On the other hand, An et al. [35] achieved up to $246.13 \mathrm{mg}$ GAE/g for lignin from corn straw recovered from a residue pretreated by steam explosion and enzymatic hydrolysis, and purified using a dioxane extraction process and dichloromethane fractionation. This higher phenolic content can be associated with the lignin fractionation that promotes the formation of new phenolic hydroxyl groups [38].

The antioxidant activity of the lignin samples was investigated in comparison with the commercial antioxidants BHT, BHA and Trolox, which were used as positive controls. The results of the DPPH• and $\mathrm{ABTS}^{*}{ }^{+}$assays are presented in Table 4 in terms of $\mathrm{IC}_{50}$ (the concentration of the tested antioxidant samples required for a $50 \%$ inhibition of radical species). The lower the $\mathrm{IC}_{50}$ value, the higher the RSA of the compounds tested.

All lignin samples presented antioxidant activity, with $\mathrm{IC}_{50}$ values ranging from 0.17 to $0.26 \mathrm{mg} / \mathrm{mL}$ in DPPH assay for HP-EOL samples and $\mathrm{IC}_{50}$ values of $0.91 \mathrm{mg} / \mathrm{mL}$ for EOL sample. This result confirmed that the lignin recovered by the integrated process achieved a remarkable improvement in its radical scavenging capacity. The commercial antioxidants Trolox, BHA and BHT present values of $0.07 \mathrm{mg} / \mathrm{mL}$, $0.04 \mathrm{mg} / \mathrm{mL}$ and $0.16 \mathrm{mg} / \mathrm{mL}$, respectively, showing a higher antioxidant potential than lignin samples. Nevertheless, some HP-EOL samples (7 and 10) presented $\mathrm{IC}_{50}$ values closer to the values obtained for BHT.

Table 4

Total phenolic and $\mathrm{IC}_{50}$ obtained by the DPPH and ABTS method of lignins, BHT, BHA and Trolox.

\begin{tabular}{llll}
\hline Assay number & $\begin{array}{l}\text { Total phenolic } \\
(\mathrm{mg} \text { GAE} / \mathrm{g})\end{array}$ & $\begin{array}{l}\mathrm{IC}_{50}(\mathrm{DPPH}) \\
(\mathrm{mg} / \mathrm{mL})\end{array}$ & $\begin{array}{l}\mathrm{IC}_{50}(\mathrm{ABTS}) \\
(\mathrm{mg} / \mathrm{mL})\end{array}$ \\
\hline 1 & $7.2 \pm 0.04$ & 0.21 & 0.027 \\
2 & $25.6 \pm 0.22$ & 0.21 & 0.022 \\
3 & $7.8 \pm 0.01$ & 0.26 & 0.028 \\
4 & $23.0 \pm 0.36$ & 0.20 & 0.022 \\
5 & $8.7 \pm 0.01$ & 0.25 & 0.016 \\
6 & $23.2 \pm 0.06$ & 0.22 & 0.016 \\
7 & $9.6 \pm 0.08$ & 0.18 & 0.020 \\
8 & $24.0 \pm 0.12$ & 0.23 & 0.023 \\
9 & $14.7 \pm 0.12$ & 0.20 & 0.020 \\
10 & $15.2 \pm 0.19$ & 0.17 & 0.018 \\
11 & $17.0 \pm 0.10$ & 0.19 & 0.018 \\
EOL & $7.5 \pm 0.04$ & 0.91 & 0.092 \\
BHT & - & 0.16 & 0.019 \\
BHA & - & 0.04 & 0.005 \\
Trolox & - & 0.07 & 0.007 \\
\hline
\end{tabular}

The antioxidant activity evaluated using ABTS presents a similar behavior.

Arshanitsa et al. [8] reported IC 50 values of $0.04-0.05 \mathrm{mg} / \mathrm{mL}$ in DPPH assay and $0.009-0.01 \mathrm{mg} / \mathrm{mL}$ in ABTS assay for BIOLIGNIN ${ }^{\mathrm{TM}}$ (lignin extracted from wheat straw using a mixture of acetic acid/formic acid/ water and further fractionation by successive extraction with dichloromethane, methanol and the mixture of methanol with dichloromethane). Lu et al. [7] reported $\mathrm{IC}_{50}$ values of $0.66 \mathrm{mg} / \mathrm{mL}$ (DPPH assay) for lignin from Acanthopanax senticosus residue, which was extracted using acetic acid-water organosolv pulping method; while AguiéBéghin et al. [39] reported $\mathrm{IC}_{50}$ around $0.33 \mathrm{mg} / \mathrm{mL}$ (DPPH assay) for organosolv and alkali lignin samples. These differences in the antioxidant capacity of the lignin samples is related to the extraction method, as well as to the source of lignocellulosic material, as commented previously $[11,12]$.

Fig. 3 shows DPPH and ABTS radical scavenging activities of commercial antioxidants (BHT, BHA and Trolox), EOL and a sample of HPEOL, as example, since the behavior of all HP-EOL was similar. BHA and Trolox were the most potent antioxidants for both assays. However, HP-EOL (sample 7) showed similar RSA to BHT in DPPH assay and higher RSA than BHT in ABTS assay, which is often used as a standard. The same behavior was observed by Sun et al. [40] that also obtained lignins with antioxidant activity higher than BHT. The RSA against stable free ABTS ${ }^{+}$radicals of HP-EOL ( sample 7) was rather close to that of antioxidant BHA, indicating that the lignin sample has potential applications as commercial antioxidants.

EOL showed the lowest antioxidant potential, achieving maximal RSA of $49.3 \%$ and $58.8 \%$ for DPPH and ABTS assays using lignin concentrations of 1.0 and $0.1 \mathrm{mg} / \mathrm{mL}$, respectively. This can be explained by the presence of carbohydrates (around 10.5\% in the EOL sample), which can decrease antioxidant activity of lignin since their polar groups may form hydrogen bonds with lignin phenolic groups [41].

Michelin et al. [22] in a previous work, studied LHW and enzymatic hydrolysis (EH) as an integrated process to obtain lignocellulose derived products, including lignin. The $\mathrm{IC}_{50}$ of the $\mathrm{EH}$ lignins were $0.5-0.75 \mathrm{mg} / \mathrm{mL}$ (DPPH assay), i.e. higher than the HP-EOL of the current work and thus with lower antioxidant capacity; this was probably due to the carbohydrate content usually present in EH lignin. An et al. [35] described IC $_{50}$ values from 0.06 to $0.15 \mathrm{mg} / \mathrm{mL}$ (DPPH assay) for lignin obtained from an integrated process, described previously. These lignins presented phenolics content of 155.4-246.3 mg GAE/g. However, in our study no relationship was found between total phenolic content and RSA among the lignin samples.

Despite several works on scavenging effects of lignin related compounds have shown that the free phenolic hydroxyl groups are crucial for lignin antioxidant activity, there are other groups that contribute to this activity (e.g. aliphatic hydroxyl group and methoxyl group). Methoxyl groups contained in lignin have been reported to act as a stabilizer for phenoxyl radicals formed during scavenging of free radicals $[42,43]$. On the other hand, the conjugated carbonyl group in the side chain has a negative effect on the antioxidant activity [5,8]. Moreover, it has been reported that the lignins with high molecular weight and polydispersity had low antioxidant activity $[5,8,40,42]$, as well as the presence of carbohydrate may influence the potential of lignins as antioxidants, as commented previously, by decreasing the concentration of the reactive phenolic functions and by changing the polarity [8]. Therefore, several factors could be influencing the RSA of lignins.

\subsection{Chemical structure of lignins}

Lignins recovered from the integrated process of LHW-EO and the direct EO process were characterized by ATR-FTIR spectroscopy, being the corresponding spectra presented in Fig. 4 . The spectra and the relative intensities of the bands were very similar, which confirmed that the "core" of the structure of lignin did not change significantly for the 

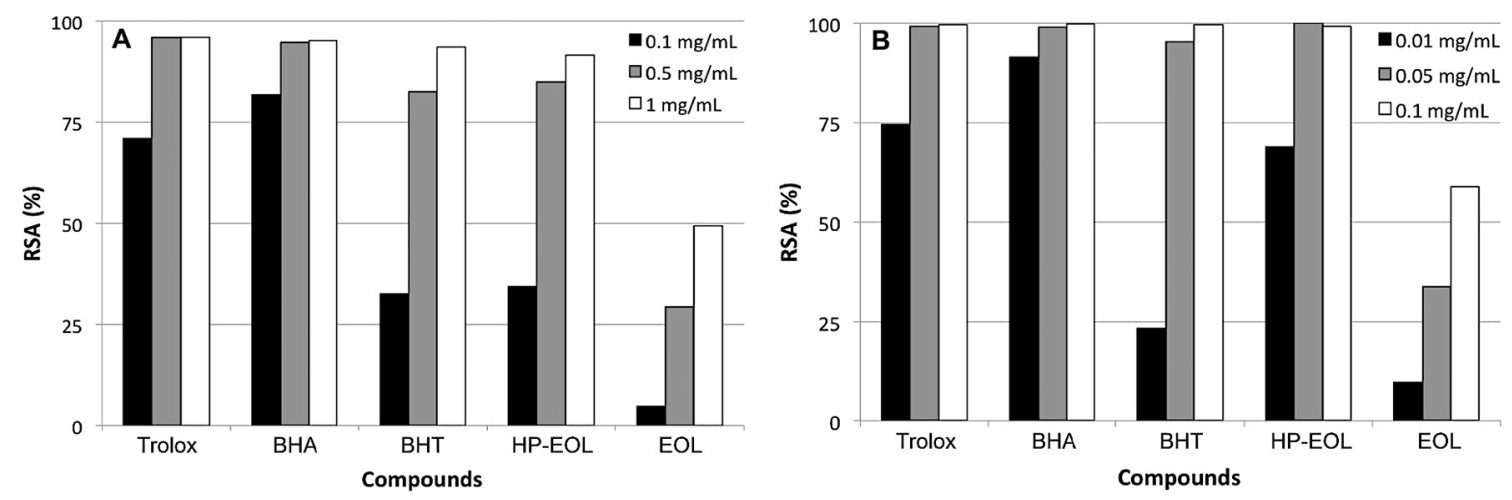

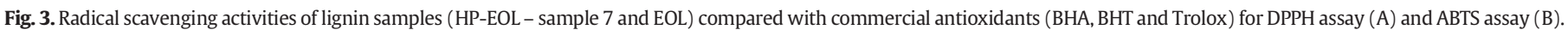

variable conditions of fractionation. However, there were some significant changes on functional groups. Bands were assigned as follows:

A wide absorption band around $3300 \mathrm{~cm}^{-1}$ is originated from the $\mathrm{O}-\mathrm{H}$ stretch. The bands at 2940 and $2840 \mathrm{~cm}^{-1}$ arise from the $\mathrm{C}-\mathrm{H}$ stretch in methyl and methylene groups [44]. These bands were less intense in 3, 4, 7, 8 and 9/10/11 lignin samples, in which the extraction time was longer (120 min), suggesting that methyl and methylene groups were removed or transformed into other chemical groups (for example $-\mathrm{C}-$ or $\mathrm{C}=0$ ) in these lignins [45]. These bands occurred at $2924 \mathrm{~cm}^{-1}$ and $2850 \mathrm{~cm}^{-1}$ for 1, 2, 5, 6 and 12 lignin samples that were extracted with short extraction time ( $40 \mathrm{~min}$ ). According to Boeriu et al. [46], bands in this region arise from the $\mathrm{C}-\mathrm{H}$ stretch in aliphatic methylene groups that can originate from fatty acids present in the lignin samples.

The absorption at $1695 \mathrm{~cm}^{-1}$ is due to the $\mathrm{C}=0$ stretch in conjugated aldehydes and carboxylic acid groups [44]. Additionally, a small shoulder was observed at $1650 \mathrm{~cm}^{-1}$ for EOL, attributed to a $\mathrm{C}=\mathrm{O}$ stretch in the conjugated carbonyl group [47]. Dizhbite et al. [5] reported that $\alpha$ carbonyl substitution in the propanoid chain decreases drastically the RSA of lignin, as commented previously. Thus, the conjugated carbonyl group in EOL was likely to cause the reduction in its antioxidant activity, discussed in the previous section.

The bands at around 1595, 1509, and $1427 \mathrm{~cm}^{-1}$, corresponding to aromatic skeletal vibrations [44], indicate that the basic aromatic structure of the lignin was not severely disrupted during pretreatment. In EOL a more intense band at $1595 \mathrm{~cm}^{-1}$ was observed than in HP-EOL, indicating a lower disruption during the pretreatment. This is explained by the single pretreatment step used on EOL sample, whereas in HP-EOL the two pretreatment steps could have increased lignin disruption. Moreover, the vibration at around $1455 \mathrm{~cm}^{-1}$ in $-\mathrm{CH}_{3}$ and $-\mathrm{CH}_{2}-$ groups was caused by asymmetric $\mathrm{C}-\mathrm{H}$ deformations.

An aliphatic $\mathrm{C}-\mathrm{H}$ stretch in $\mathrm{CH}_{3}$ groups was observed at $1365 \mathrm{~cm}^{-1}$ [44]. Abdelkafi et al. [48] observed a stronger band at $1365 \mathrm{~cm}^{-1}$ in acetylated lignin preparations, suggesting that natural acetylation occurs in lignin samples extracted with neutral solvent. Phenolic $\mathrm{OH}$ groups are also shown by absorption bands at $1365 \mathrm{~cm}^{-1}, 1330 \mathrm{~cm}^{-1}$ and $1218 \mathrm{~cm}^{-1}$ [49]. The absence of some of these bands for EOL indicates a small phenolic $\mathrm{OH}$ groups content, that is consistent with the results of total phenolic and antioxidant activity. In the organosolv process $\beta$ O-4-linkages are cleaved generating both phenolic hydroxyl $\left(1365 \mathrm{~cm}^{-1}\right.$ ) and carbonyl groups (around $1700 \mathrm{~cm}^{-1}$ ) [49,50].

Several bands were attributed to syringyl (S) and guaiacyl (G) structures. Syringyl ring breathing with C-O stretching are seen at around $1328 \mathrm{~cm}^{-1}$. Additionally, a typical infrared band of $\mathrm{S}$ structure at $1115 \mathrm{~cm}^{-1}$ was originated from aromatic $\mathrm{C}-\mathrm{H}$ in-plane deformation. These bands were absent or less evident in EOL, suggesting a lower percentage of $\mathrm{S}$ unit in this lignin sample.

A typical $G$ bands was observed at around $1260 \mathrm{~cm}^{-1}$ ( $\mathrm{G}$ ring plus $\mathrm{C}=\mathrm{O}$ stretch) for HP-EOL [44]. However, for EOL a more accentuated band was detected at $1250 \mathrm{~cm}^{-1}$. The band at around $1030 \mathrm{~cm}^{-1}$ is attributed to aromatic $\mathrm{C}-\mathrm{H}$ in-plane deformation vibrations $(\mathrm{G}>\mathrm{S})$, and this was bigger for EOL [44]. Bands in the region between 1000 and $1300 \mathrm{~cm}^{-1}$ are related to the carbohydrate content in lignin [46]. So, the bands at around $1250,1160,1115,1030 \mathrm{~cm}^{-1}$ are an indicative of

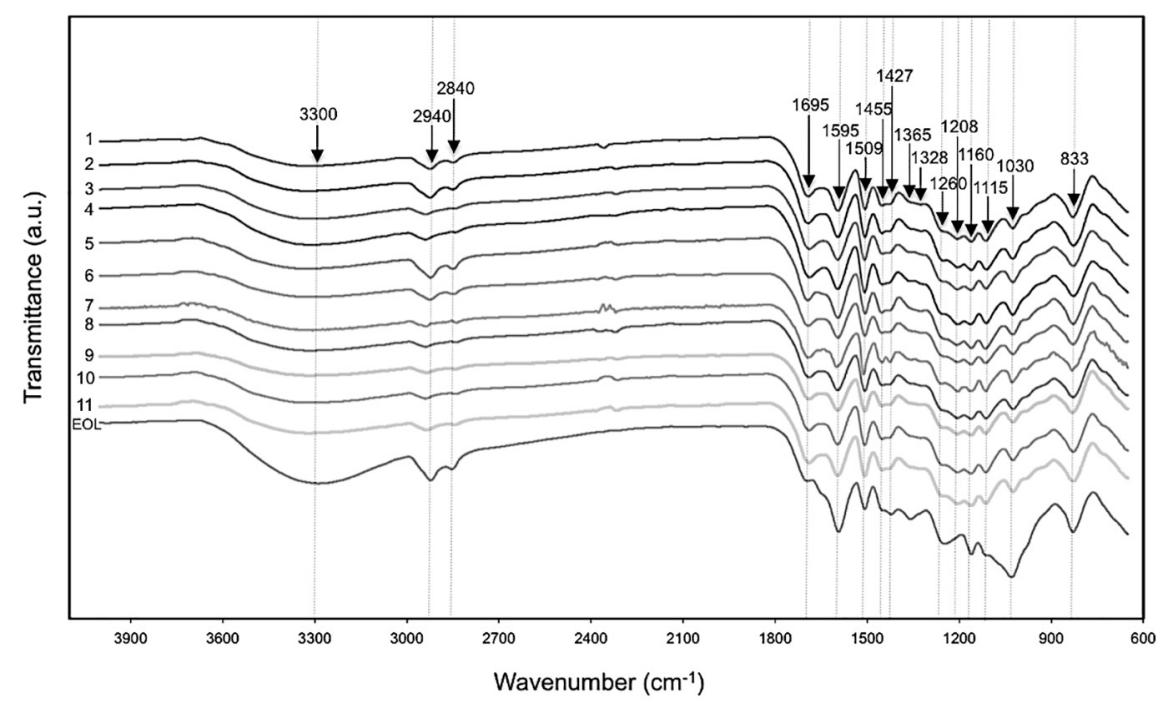

Fig. 4. ATR-FTIR spectra of hydrothermally pretreated ethanol organosolv lignin (HP-EOL - samples 1 to 11) and ethanol organosolv lignin (EOL) from corncob. 
hemicelluloses [51-53]. Therefore, the influence of hemicellulose impurities on the spectral profile was more visible for EOL and is in agreement with the results of chemical composition of lignin on Table 3.

Another important spectral feature of HGS lignin is the intense band at around $833 \mathrm{~cm}^{-1}$ (C-H out-of-plane in positions 2 and 6 of S units, and in all position of $\mathrm{H}$ units) [44]. Moreover, the presence of the band at $1160 \mathrm{~cm}^{-1}$ ( $\mathrm{p}$ coumaryl unit, $\mathrm{H}$ ) always allows a clear assignment to the HGS type. This band was more evident in EOL than HP-EOL, confirming that the studied lignins are of the HGS type. On the other hand, An et al. [35] reported that the increasing intensity of signal at $1160 \mathrm{~cm}^{-1}$ revealed that the lignin from corn straw with higher molecular weight had a high content of $\mathrm{H}$ unit. They suggested that during the pretreatment, lignin fragments with $\mathrm{H}$ units were easier to condense and to form lignin with high molecular weight. So, the higher intensity band at $1160 \mathrm{~cm}^{-1}$ for EOL suggests higher molecular weight for EOL than HP-EOL. Additionally, the band at around $1160 \mathrm{~cm}^{-1}$ indicates $\mathrm{C}=\mathrm{O}$ vibrations in conjugated ester groups [44].

\subsection{Thermal degradation of lignins}

The thermal degradation of lignin can be affected by its inherent structure, degrees of branching and condensation and functional groups [54]. So, in order to understand the relationship between the structural and thermal properties of the extracted lignins, TGA was applied to study the thermal properties of HP-EOL, as well as to EOL.

The thermal decomposition of lignin is a complex process and happens slowly over a wide temperature range, with the most extensive mass loss (40-50\% of the dried sample) in temperatures ranging from 230 to $500{ }^{\circ} \mathrm{C}$ for LWH-EOL and from 175 to $540{ }^{\circ} \mathrm{C}$ for EOL. This occurs because the complex structure of lignin, composed of phenolic hydroxyl, benzylic hydroxyl, and carbonyl groups, have different thermal stability, and then events occurring at different temperatures [55].

Several stages of weight-loss can be observed in the DTG curves. Initially, a small weight loss ( $<3 \%$ of weight loss) was firstly observed below $100{ }^{\circ} \mathrm{C}$, which is justified by the residual moisture present in the lignin samples. The weight loss related to lignin degradation started at around $230-253^{\circ} \mathrm{C}\left(T_{\text {onset }}\right)$ for HP-EOL and $175^{\circ} \mathrm{C}$ for EOL. This fact, in the latter case, can be related to a small presence of hemicelluloses that decomposes at lower temperatures (see Table 3). Two main degradation events (DTG curve) were detected during the lignin decomposition, that occurred at $301-319{ }^{\circ} \mathrm{C}$ (peak 1 ) and $344-378{ }^{\circ} \mathrm{C}$ (peak 2) for HPEOL; and at $198{ }^{\circ} \mathrm{C}$ (peak 1 ) and 282 (peak 2) for EOL.

According to Laurichesse and Avérous [56], the decomposition of the lignin structure starts at relatively low temperatures, i.e., $150-275^{\circ} \mathrm{C}$, as observed in our work. It is thought that the first decomposition step is due to the dehydration of the hydroxyl groups located in the benzyl group. Between 150 and $300{ }^{\circ} \mathrm{C}$ occurs the cleavage of $\alpha$ - and $\beta$ aryl alkyl ether linkages. Aliphatic side chains start splitting off from the aromatic ring at around $300{ }^{\circ} \mathrm{C}$, while at $370-400{ }^{\circ} \mathrm{C}$ occurs the carbon carbon cleavage between lignin structural units.

Finally, at temperatures $>500{ }^{\circ} \mathrm{C}$, the typical weight losses in TG curves flatten out, with a slow release of the volatile products (such as $\left.\mathrm{CO}, \mathrm{CO}_{2}, \mathrm{CH}_{4}, \mathrm{H}_{2}\right)$, before the formation of (30-50\%) char [56,57]. In our study, $40 \%$ lignin samples remained unvolatilized at $800{ }^{\circ} \mathrm{C}$ (char residue), due to the formation of highly condensed aromatic structures. The decomposition temperature strongly depends on the molecular structure of lignin. In general, the pretreatment has a significant effect on the thermal stability of the produced lignin products, which can explain the main differences between HP-EOL and EOL. Table 5 summarizes the main events occurred during thermogravimetric analysis.

Representative TG and DTG curves of HP-EOL and EOL are presented on Fig. 5, which are in good agreement with the thermogravimetric behavior verified in other works [51,58-60].

\subsection{Glass transition of lignins}

DSC is the most common technique used to determine glass transition temperatures $\left(T_{g}\right)$, as well as the thermal behavior of polymers. The $T_{g}$ is correlated to the viscoelastic behavior of amorphous polymers $[61,62]$. At temperatures below the $T_{g}$ the materials are hard and glassy. This hardness decreases in the region of transition and the material shows a viscous or rubbery state as the temperature increases [49].

Lignin behaves as an amorphous thermoplastic material, exhibiting a $T_{g}$ that varies widely depending on the extraction method, water content, molecular weight, chemical modification, and thermal history $[56,63]$. It is an important parameter to know when considering the use of lignins in polymer applications, but it is often difficult to determine due to the broad heterogeneity of the lignin structure and molecular weight [64].

Different underivatized lignin preparations are reported to have $T_{g}$ values between 90 and $180^{\circ} \mathrm{C}$ [65,66], corresponding the lower values to organosolv lignins and the higher ones usually to softwood kraft lignins $[58,65,67]$. HP-EOL have shown $T_{g}$ values in the range from 60 to 90 ${ }^{\circ} \mathrm{C}$ (Table 5), i.e. in general, the HP-EOL presented lower $T_{g}$ values than the ones reported for organosolv lignins.

According to Kubo and Kadla [68], the variations in $T_{g}$ values for the lignins illustrate mainly the variations in their chemical structure, which can be correlated to the degree of crosslinking, the variations in the flexibility of the polymeric chains, and the amount of impurities. Structurally, it has been reported that lignin samples with a high $S$ and low $G$ content would exhibit low $T_{g}$; and lignin samples with low $T_{g}$ have less charred residues [69]. Still, organosolv lignins have a more oxidized structure, a relatively higher amount of phenolic hydroxyl groups, high purity, low $T_{g}$ and are easy to thermally process $[64,67]$.

Additionally, the extraction methods also have shown a great influence on the final structure and properties of lignin [64]. For example,

Table 5

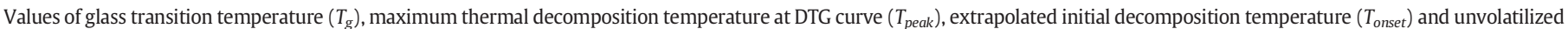
weight fraction at $800{ }^{\circ} \mathrm{C}$ (char residue) for HP-EOL and EOL.

\begin{tabular}{|c|c|c|c|c|c|c|}
\hline Sample & $T_{g}\left({ }^{\circ} \mathrm{C}\right)$ & $T_{\text {peak } 1}\left({ }^{\circ} \mathrm{C}\right)$ & $T_{\text {peak } 2}\left({ }^{\circ} \mathrm{C}\right)$ & $T_{\text {onset }}\left({ }^{\circ} \mathrm{C}\right)$ & Maximal weigh loss (\%) & Char $_{800}(\%)$ \\
\hline 1 & $75.3 \pm 1.25$ & 301.0 & 343.6 & 234.6 & 44.9 & 41.2 \\
\hline 2 & $90.3 \pm 4.33$ & 306.6 & 348.3 & 241.0 & 42.2 & 42.6 \\
\hline 3 & $86.3 \pm 0.29$ & 301.4 & 361.9 & 240.1 & 41.4 & 42.2 \\
\hline 4 & $60.3 \pm 1.74$ & 306.4 & 362.1 & 238.9 & 43.1 & 40.0 \\
\hline 5 & $64.1 \pm 0.33$ & 302.2 & 367.8 & 227.5 & 44.8 & 39.3 \\
\hline 6 & $75.2 \pm 0.76$ & 304.7 & 361.5 & 250.6 & 48.7 & 39.3 \\
\hline 7 & $68.0 \pm 0.62$ & 313.8 & 366.4 & 241.4 & 47.4 & 39.1 \\
\hline 8 & $78.2 \pm 0.30$ & 318.5 & 374.2 & 252.7 & 46.0 & 41.3 \\
\hline 9 & $62.9 \pm 1.17$ & 306.4 & 377.5 & 239.1 & 44.5 & 40.9 \\
\hline 10 & $63.9 \pm 1.34$ & 311.5 & 366.4 & 243.6 & 44.1 & 39.9 \\
\hline 11 & $60.3 \pm 1.74$ & 309.1 & 381.0 & 241.0 & 44.6 & 41.2 \\
\hline EOL & n.d. & 198.6 & 281.9 & 175.0 & 51.2 & 39.7 \\
\hline
\end{tabular}

n.d. not detected. 


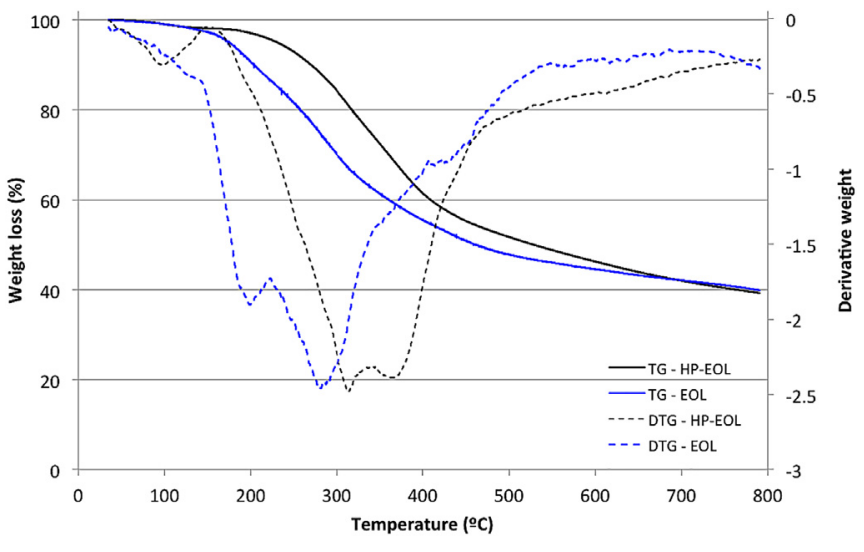

Fig. 5. TG (solid lines) and DTG (dotted lines) curves of hydrothermally pretreated ethanol organosolv lignin (HP-EOL - sample 7) and ethanol organosolv lignin (EOL) from corncob.

Huijgen et al. [70] have reported organosolv lignins with $T_{g}$ between 87 and $133^{\circ} \mathrm{C}$, where the high process temperature (i.e. high severity) seems to reduce the $T_{g}$. Therefore, the lower $T_{g}$ observed for HP-EOL can be related to the integrated process, since a high severity HP pretreatment step was performed previously the organosolv process.

Other authors also reported low $T_{g}$ for the studied lignins. For example, Hansen et al. [49] reported $T_{g}$ value of $75{ }^{\circ} \mathrm{C}$ for LigSteam (resulted from an acid steam explosion process using wheat straw as raw material); and Luong et al. [59] have reported $T_{g}$ values $46{ }^{\circ} \mathrm{C}$ for ligninSKKU. It was not possible to determine the $T_{g}$ value for EOL in DSC curve. So, it was not possible to correlate the structure and extraction methods of HP-EOL and EOL based on the $T_{g}$ values.

\section{Conclusions}

The combination of the LHW and EO as an integrated process, allowed the complete removal of hemicellulose in the first step and the recovery of solids with a high cellulose content (60.4\%) and lignin (33\%). The use of organosolv process on LHW-pretreated corncob recovered fractions with $>60 \%$ delignification, good glucan preservation (almost 90\%) in the solid residues (or cellulose pulp) and lignin with high purity ( $>90 \%)$. On the other hand, the EO process of untreated corncob recovered a lignin sample (approx. 55\%) with 10.32\% carbohydrate, and a solid fraction with a high hemicellulose content $(51.47 \%$ cellulose, $31.86 \%$ hemicellulose, and $11.61 \%$ of Klason lignin). Therefore, an effective separation of the three components was achieved on the integrated process. FTIR and TGA analyses proved that the different extraction strategies had great influence on lignin structure and cellulose pulp. Lignin antioxidant capacity indicated the lignin obtained by integrated process had the highest antioxidant activity, that was similar to some commercial antioxidants. This finding opens the possibility for lignin application in several industrial sectors, including food and pharmaceutical.

\section{Acknowledgements}

Michele Michelin is a recipient of a FCT fellowship (SFRH/BPD/ 100786/2014). This study was supported by the Portuguese Foundation for Science and Technology (FCT) under the scope of the strategic funding of UID/BIO/04469/2013 unit and COMPETE 2020 (POCI-010145-FEDER-006684) and BioTecNorte operation (NORTE-01-0145FEDER-000004) funded by the European Regional Development Fund under the scope of Norte2020 - Programa Operacional Regional do Norte. The authors thank André Mota and CVR - "Centro para a Valorização de Resíduos", (Guimarães, Portugal) for supporting the gridding of the material; Paula Pereira and Maura Guimarães for the technical support.

\section{References}

[1] O.Y. Abdelaziz, D.P. Brink, J. Prothmannc, K. Ravi, M. Sun, J. García-Hidalgo, M. Sandahl, C.P. Hulteberg, C. Turner, G. Lidén, M.F. Gorwa-Grauslund, Biological valorization of low molecular weight lignin, Biotechnol. Adv. 34 (2016) 1318-1346.

[2] S. Laurichesse, L. Avérous, Synthesis, thermal properties, rheological and mechanical behaviors of lignins-grafted-poly(e-caprolactone), Polymer 54 (2013) 3882-3890.

[3] R. Kumar, Global Antioxidants Market: Trends \& Opportunities (2013-2018), Daedal Research, Delhi, 2013.

[4] M. Taghvaei, S.M. Jafari, Application and stability of natural antioxidants in edible oils in order to substitute synthetic additives, J. Food Sci. Technol. 52 (3) (2015) 1272-1282.

[5] T. Dizhbite, G. Telysheva, V. Jurkjane, U. Viesturs, Characterization of the radical scavenging activity of lignins - natural antioxidants, Bioresour. Technol. 95 (2004) 309-317.

[6] D. Amendola, D.M. De Faveri, I. Egües, L. Serrano, J. Labidi, G. Spigno, Autohydrolysis and organosolv process for recovery of hemicelluloses, phenolic compounds and lignin from grape stalks, Bioresour. Technol. 107 (2012) 267-274.

[7] Q. Lu, W. Liu, L. Yang, Y. Zu, B. Zu, M. Zhu, Y. Zhang, X. Zhang, R. Zhang, Z. Sun, J. Huang, X. Zhang, W. Li, Investigation of the effects of different organosolv pulping methods on antioxidant capacity and extraction efficiency of lignin, Food Chem. 131 (2012) 313-317.

[8] A. Arshanitsa, J. Ponomarenko, T. Dizhbite, A. Andersone, R.J.A. Gosselink, J. van der Putten, M. Lauberts, G. Telysheva, Fractionation of technical lignins as a tool for improvement of their antioxidant properties, J. Anal. Appl. Pyrolysis 103 (2013) 78-85.

[9] L.B. Brenelli, F. Mandelli, A.Z. Mercadante, G.J.M. Rocha, S.A. Rocco, A.F. Craievich, A.R. Gonçalves, D.C. Centeno, M.O. Neto, F.M. Squina, Acidification treatment of lignin from sugarcane bagasse results infractions of reduced polydispersity and high free-radical scavenging capacity, Ind. Crop. Prod. 83 (2016) 94-103.

[10] A. Barapatre, A.S. Meena, S. Mekala, A. Das, H. Jha, In vitro evaluation of antioxidant and cytotoxic activities of lignin fractions extracted from Acacia nilotica, Int. J. Biol. Macromol. 86 (2016) 443-453.

[11] J.H. Lora, W.G. Glasser, Recent industrial applications of lignin: a sustainable alternative to nonrenewable materials, J. Polym. Environ. 10 (1/2) (2002) 39-48.

[12] K. Wörmeyer, T. Ingram, B. Saake, G. Brunner, I. Smirnova, Comparison of different pretreatment methods for lignocellulosic materials. Part II: influence of pretreatment on the properties of rye straw lignin, Bioresour. Technol. 102 (2011) 4157-4164.

[13] M.E. Vallejos, M.D. Zambon, M.C. Area, A.A.S. Curvelo, Low liquid-solid ratio fractionation of sugarcane bagasse by hot water autohydrolysis and organosolv delignification, Ind. Crop. Prod. 65 (2015) 349-353.

[14] A. Romaní, G. Garrote, F. López, J.C. Parajó, Eucalyptus globulus wood fractionation by autohydrolysis and organosolv delignification, Bioresour. Technol. 102 (2011) 5896-5904.

[15] H.A. Ruiz, A.A. Vicente, J.A. Teixeira, Kinetic modeling of enzymatic saccharification using wheat straw pretreated under autohydrolysis and organosolv process, Ind. Crop. Prod. 36 (2012) 100-107.

[16] M.-Q. Zhu, J.-L. Wen, Y.-Q. Su, Q. Wei, R.-C. Sun, Effect of structural changes of lignin during the autohydrolysis and organosolv pretreatment on Eucommia ulmoides Oliver for an effective enzymatic hydrolysis, Bioresour. Technol. 185 (2015) 378-385

[17] A.J. Ragauskas, G.T. Beckham, M.J. Biddy, R. Chandra, F. Chen, M.F. Davis, B.H. Davison, R.A. Dixon, P. Gilna, M. Keller, P. Langan, A.K. Naskar, J.N. Saddler, T.J. Tschaplinski, G.A. Tuskan, C.E. Wyman, Lignin valorization: improving lignin processing in the biorefinery, Science 344 (2014) 1246843.

[18] J.-L. Wen, S.-N. Sun, T.-Q. Yuan, F. Xu, R.-C. Sun, Fractionation of bamboo culms by autohydrolysis, organosolv delignification and extended delignification: understanding the fundamental chemistry of the lignin during the integrated process, Bioresour. Technol. 150 (2013) 278-286.

[19] R.E. Hage, L. Chrusciel, L. Desharnais, N. Brosse, Effect of autohydrolysis of Miscanthus $x$ giganteus on lignin structure and organosolv delignification, Bioresour. Technol. 101 (2010) 9321-9329.

[20] L.V.A. Gurgel, M.T.B. Pimenta, A.A.S. Curvelo, Ethanol-water organosolv delignification of liquid hot water (LHW) pretreated sugarcane bagasse enhanced by high-pressure carbon dioxide (HP-CO $)$, Ind. Crop. Prod. 94 (2016) 942-950.

[21] M.H. Hussin, A.A. Rahim, M.N.M. Ibrahim, M. Yemloul, D. Perrin, N. Brosse, Investigation on the structure and antioxidant properties of modified lignin obtained by different combinative processes of oil palm fronds (OPF) biomass, Ind. Crop. Prod. 52 (2014) 544-551.

[22] M. Michelin, H.A. Ruiz, M.L.T.M. Polizeli, J.A. Teixeira, Multi-step approach to add value to corncob: production of biomass degrading enzymes, lignin and fermentable sugars, Bioresour. Technol. 247 (2018) 582-590.

[23] L.P. Novo, L.V.A. Gurgel, K. Marabezi, A.A.S. Curvelo, Delignification of sugarcane bagasse using glycerol-water mixtures to produce pulps for saccharification, Bioresour. Technol. 102 (2011) 10040-10046.

[24] A. Sluiter, B. Hames, R. Ruiz, C. Scarlata, J. Sluiter, D. Templeton, D. Crocker, Determination of structural carbohydrates and lignin in biomass, NREL - LAP. Technical Report NREL/TP-510-42618, 2008.

[25] A. Sluiter, B. Hames, R. Ruiz, C. Scarlata, J. Sluiter, D. Templeton, D. Crocker, Determination of sugars, byproducts, and degradation products in liquid fraction process samples, NREL - LAP. Technical Report NREL/TP-510-42623, 2006.

[26] H.P.S. Makkar, M. Blummel, N.K. Borowy, K. Becker, Gravimetric determination of tannins and their correlations with chemical and protein precipitation methods, J. Sci. Food Agric. 61 (1993) 161-165.

[27] M.S. Blois, Antioxidant determination by the use of a stable free radical, Nature 181 (1958) 1199-1200. 
28] R. Re, N. Pellegrini, A. Proteggente, A. Pannala, M. Yang, C. Rice-Evans, Antioxidant activity applying an improved ABTS radical cation decolorization assay, Free Radic. Biol. Med. 26 (9/10) (1999) 1231-1237.

[29] G. Garrote, E. Falqué, H. Domínguez, J.C. Parajó, Autohydrolysis of agricultural residues: study of reaction byproducts, Bioresour. Technol. 98 (2007) 1951-1957.

[30] D. Nabarlatz, A. Ebringerová, D. Montané, Autohydrolysis of agricultural by-products for the production of xylo-oligosaccharides, Carbohydr. Polym. 69 (2007) 20-28.

31] N. Xie, N. Jiang, M. Zhang, W. Qi, R. Su, Z. He, Effect of different pretreatment methods of corncob on bioethanol production and enzyme recovery, Cellul. Chem. Technol. 48 (3-4) (2014) 313-319.

[32] M. Michelin, J.A. Teixeira, Liquid hot water pretreatment of multi feedstocks and enzymatic hydrolysis of solids obtained thereof, Bioresour. Technol. 216 (2016) 862-869.

[33] M. Leschinsky, G. Zuckerstatter, H.K. Weber, R. Patt, H. Sixta, Effect of autohydrolysis of Eucalyptus globulus wood on lignin structure. Part 1: comparison of different lignin fractions formed during water prehydrolysis, Holzforschung 62 (2008) 645-652.

[34] M. Leschinsky, G. Zuckerstatter, H.K. Weber, R. Patt, H. Sixta, Effect of autohydrolysis of Eucalyptus globulus wood on lignin structure. Part 2: influence of autohydrolysis intensity, Holzforschung 62 (2008) 653-658.

[35] L. An, G. Wang, H. Jia, C. Liu, W. Sui, C. Si, Fractionation of enzymatic hydrolysis lignin by sequential extraction for enhancing antioxidant performance, Int. J. Biol. Macromol. 99 (2017) 674-681.

[36] D. Pasquini, M.T.B. Pimenta, L.H. Ferreira, A.A.S. Curvelo, Extraction of lignin from sugar cane bagasse and Pinus taeda wood chips using ethanol-water mixtures and carbon dioxide at high pressures, J. Supercrit. Fluids 36 (2005) 31-39.

[37] S.S. Qazi, D. Li, C. Briens, F. Berruti, M.M. Abou-Zaid, Antioxidant activity of the lignins derived from fluidized-bed fast pyrolysis, Molecules 22 (372) (2017) 1-14.

[38] P. Ma, Y. Gao, H. Zhai, Fractionated wheat straw lignin and its application as antioxidant, Bioresources 8 (4) (2013) 5581-5595.

[39] V. Aguié-Béghin, L. Foulon, P. Soto, D. Crônier, E. Corti, F. Legée, L. Cézard, B. Chabbert, M.-N. Maillard, W.J.J. Huijgen, S. Baumberger, Use of food and packaging model matrices to investigate the antioxidant properties of biorefinery grass lignins, J. Agric. Food Chem. 63 (2015) 10022-10031.

[40] S.-N. Sun, X.-F. Cao, F. Xu, G.L. Jones, M. Baird, Alkaline and organosolv lignins from furfural residue: structural features and antioxidant activity, Bioresources 9 (1) (2014) 772-785

[41] V. Ugartondo, M. Mitjans, M.P. Vinardell, Comparative antioxidant and cytotoxic effects of lignins from different sources, Bioresour. Technol. 99 (2008) 6683-6687.

[42] X.J. Pan, J.F. Kadla, K. Ehara, N. Gilkes, J.N. Saddler, Organosolv ethanol lignin from hybrid poplar as a radical scavenger: relationship between lignin structure, extraction conditions, and antioxidant activity, J. Agric. Food Chem. 54 (16) (2006) 5806-5813.

[43] I. Sumerskii, T. Zweckmair, H. Hettegger, G. Zinovyev, M. Bacher, T. Rosenau, A. Potthast, A fast track for the accurate determination of methoxyl and ethoxyl groups in lignin, RSC Adv. 7 (2017) 22974-22982.

[44] O. Faix, Classification of lignins from different botanical origins by FT-IR spectroscopy, Holzforschung 45 (1991) 21-27.

[45] X. Lu, X. Zheng, X. Li, J. Zhao, Adsorption and mechanism of cellulase enzymes onto lignin isolated from corn stover pretreated with liquid hot water, Biotechnol. Biofuels 9 (118) (2016) 1-12.

[46] C.G. Boeriu, D. Bravo, R.J.A. Gosselink, J.E.G. van Dam, Characterisation of structuredependent functional properties of lignin with infrared spectroscopy, Ind. Crop. Prod. 20 (2004) 205-218.

[47] Y.-Y. Bai, L.-P. Xiao, Z.-J. Shi, R.-C. Sun, Structural variation of bamboo lignin before and after ethanol organosolv pretreatment, Int. J. Mol. Sci. 14 (2013) 21394-21413.

[48] F. Abdelkafi, H. Ammar, B. Rousseau, M. Tessier, R.E. Gharbi, A. Fradet, Structura analysis of alfa grass (Stipa tenacissima L.) lignin obtained by acetic acid/formic acid delignification, Biomacromolecules 12 (2011) 3895-3902.

[49] B. Hansen, P. Kusch, M. Schulze, B. Kamm, Qualitative and quantitative analysis of lignin produced from beech wood by different conditions of the organosolv process, J. Polym. Environ. 24 (2016) 85-97.
[50] H. Nimz, Das Lignin der Buche-Entwurf eines Konstitutionsschemas, Angew. Chem. 9 (1974) 336-344.

[51] M.G. Alriols, A. Tejado, M. Blanco, I. Mondragon, J. Labidi, Agricultural palm oil tree residues as raw material for cellulose, lignin and hemicelluloses production by ethylene glycol pulping process, Chem. Eng. J. 148 (2009) 106-114.

[52] C.K. Nitsos, K.A. Matis, K.S. Triantafyllidis, Optimization of hydrothermal pretreatment of lignocellulosic biomass in the bioethanol production process, ChemSusChem 6 (2013) 110-122.

[53] C.A.E. Costa, W. Coleman, M. Dube, A.E. Rodrigues, P.C.R. Pinto, Assessment of key features of lignin from lignocellulosic crops: stalksand roots of corn, cotton, sugarcane, and tobacco, Ind. Crop. Prod. 92 (2016) 136-148.

[54] X. Chen, H. Li, S. Sun, X. Cao, R. Sun, Effect of hydrothermal pretreatment on the structural changes of alkaline ethanol lignin from wheat straw, Sci. Rep. 6 (39354) (2016) 1-9.

[55] J.C. Domínguez, M. Oliet, M.V. Alonso, M.A. Gilarranz, F. Rodríguez Thermal stability and pyrolysis kinetics of organosolv lignins obtained from Eucalyptus globulus, Ind. Crop. Prod. 27 (2008) 150-156.

[56] S. Laurichesse, L. Avérous, Chemical modification of lignins: towards biobased polymers, Prog. Polym. Sci. 39 (7) (2014) 1266-1290.

[57] J.-L. Wen, S.-L. Sun, B.-L. Xue, R.-C. Sun, Quantitative structures and thermal properties of birch lignins after ionic liquid pretreatment, J. Agric. Food Chem. 61 (3) (2013) 635-645.

[58] A. Tejado, C. Peña, J. Labidi, J.M. Echeverria, I. Mondragon, Physico-chemical characterization of lignins from different sources for use in phenol-formaldehyde resin synthesis, Bioresour. Technol. 98 (2007) 1655-1663.

[59] N.D. Luong, N.T.T. Binh, L.D. Duong, D.O. Kim, D.-S. Kim, S.H. Lee, B.J. Kim, Y.S. Lee, J.D. Nam, An eco-friendly and efficient route of lignin extraction from black liquor and a lignin-based copolyester synthesis, Polym. Bull. 68 (2012) 879-890.

[60] S. Zhou, Y. Xue, A. Sharma, X. Bai, Lignin valorization through thermochemical conversion: comparison of hardwood, softwood and herbaceous lignin, ACS Sustain. Chem. Eng. 4 (12) (2016) 6608-6617.

[61] W.G. Glasser, Classification of lignin according to chemical and molecular structure, in: W.G. Glasser, R.A. Northey, T.P. Shultz (Eds.), Lignin: Historical, Biological, and Materials Perspectives, American Chemical Society, Washington D.C. 2000, pp. 216-238.

[62] T. Hatakeyama, H. Hatakeyama, Lignin, in: T. Hatakeyama, H. Hatakeyama (Eds.), Thermal Properties of Green Polymers and Biocomposites, Kluwer Academic Publishers 2005, pp. 171-215.

[63] W.O.S. Doherty, P. Mousavioun, C.M. Fellows, Value-adding to cellulosic ethanol: lignin polymers, Ind. Crop. Prod. 33 (2) (2011) 259-276.

[64] O. Gordobil, R. Moriana, L. Zhang, J. Labidi, O. Sevastyanova, Assesment of technical lignins for uses in biofuels and biomaterials: structure-related properties, proximate analysis and chemical modification, Ind. Crop. Prod. 83 (2016) 155-165.

[65] W.G. Glasser, R.K. Jain, Lignin derivatives. I. Alkanoates, Holzforschung 47 (1993) 225-233.

[66] D. Feldman, D. Banu, J. Campanelly, H. Zhu, Blends of vinylic copolymer with plasticized lignin: thermal and mechanical properties, J. Appl. Polym. Sci. 81 (2001) 861-874.

[67] R.J. Sammons, D.P. Harper, N. Labbé, J.J. Bozell, T. Elder, T.G. Rials, Characterization of organosolv lignins using thermal and FT-IR spectroscopic analysis, Bioresources 8 (2) (2013) 2752-2767.

[68] S. Kubo, J.F. Kadla, Poly(ethylene oxide)/organosolv lignin blends: relationship between thermal properties, chemical structure, and blend behavior, Macromolecules 37 (18) (2004) 6904-6911.

[69] Q. Sun, R. Khunsupat, K. Akato, J. Tao, N. Labbé, N.C. Gallego, J.J. Bozell, T.G. Rials, G.A. Tuskan, T.J. Tschaplinski, A.K. Naskar, Y. Puf, A.J. Ragauskas, A study of poplar organosolv lignin after melt rheology treatment as carbon fiber precursors, Green Chem. 18 (2016) 5015-5024

[70] W.J.J. Huijgen, G. Telysheva, A. Arshanitsa, R.J.A. Gosselink, P.J. de Wild, Characteristics of wheat straw lignins from ethanol-based organosolv treatment, Ind. Crop. Prod. 59 (2014) 85-95. 